\title{
Body mass index of patients with chronic obstructive pulmonary disease is associated with pulmonary function and exacerbations: a retrospective real world research
}

\author{
Zhenchao Wu ${ }^{1,2 \#}$, Dong Yang ${ }^{3 \#}$, Zhengwei $\mathrm{Ge}^{4}$, Mengdie $\mathrm{Yan}^{4}$, Nan $\mathrm{Wu}^{4}$, Yi Liu ${ }^{1}$ \\ ${ }^{1}$ Department of Respiratory, Shandong Provincial Hospital Affiliated to Shandong University, Jinan 250021, China; ${ }^{2}$ School of Medicine and Life \\ Sciences, University of Jinan-Shandong Academy of Medical Sciences, Jinan 250022, China; ${ }^{3}$ Department of Respiratory, Zhongshan Hospital, \\ Fudan University, Shanghai 200032, China; ${ }^{4}$ Shandong University, Jinan 250100, China \\ Contributions: (I) Conception and design: Y Liu, Z Wu; (II)Administrative support: Y Liu, D Yang; (III)Provision of study materials or patients: Y \\ Liu, D Yang; (IV) Collection and assembly of data: Z Wu, Z Ge, M Yan, N Wu; (V) Data analysis and interpretation: Z Wu, M Yan, Z Ge; (VI) \\ Manuscript writing: All authors; (VII) Final approval of manuscript: All authors. \\ "These authors contributed equally to this work. \\ Correspondence to: Dr. Yi Liu. Department of Respiratory, Shandong Provincial Hospital Affiliated to Shandong University, No. 324 Jingwuweiqi \\ Road, Huaiyin District, Jinan 250021, China. Email: yiliu_sdu@163.com.
}

Background: Chronic obstructive pulmonary disease (COPD) is prevalent in China. The role of body mass index (BMI) in COPD progression and prognosis is unclear. We analyzed the association between BMI and pulmonary function, inflammation levels and exacerbation in Chinese COPD patients.

Methods: Our retrospective real world research included 744 patients with COPD diagnosed by spirometry and hospitalized from January 1st, 2014 to December 31st, 2016. The indicators were gathered from hospital records database and frequency of exacerbation in the three years were followed up. All 744 patients were divided into four groups by BMI grades. We analyzed the association between BMI and pulmonary function, inflammation levels and exacerbation by Spearman bivariate correlations, Kruskal-Wallis test, MannWhitney $\mathrm{U}$ test and logistic regression.

Results: The singly proportion (median of BMI) of these patients in underweight, normal weight, overweight and obesity was $7.80 \%$ (17.54), 45.97\% (22.12), 27.96\% (27.00) and $18.28 \%$ (31.25) respectively. With increasing of BMI grades, the values of forced expiratory volume in 1 second $\left(\mathrm{FEV}_{1}\right)$, peak expiratory flow (PEF), forced expiratory flow (FEF25/50/75) and diffusing capacity of carbon monoxide (DLCO) were correspondingly increasing; the percentage of neutrophils and C-reactive protein (CRP) presented significant declining trend while the trend of the percentage of eosinophils was negative; the dose of systemic corticosteroid and length of stay present decreasing tendency; the frequency of exacerbation and hospitalization were decreasing. These were similar results in gender, smoking status COPD subgroups.

Conclusions: In our study, BMI was moderately correlated with pulmonary function positively and exacerbations negatively. To some extent, BMI might be a useful indicator to predict the prognosis of COPD patients and for long-term management.

Keywords: Chronic obstructive pulmonary disease (COPD); body mass index (BMI); prognosis; pulmonary function; exacerbation

Submitted May 26, 2018. Accepted for publication Aug 07, 2018.

doi: $10.21037 /$ jtd.2018.08.67

View this article at: http://dx.doi.org/10.21037/jtd.2018.08.67 


\section{Introduction}

In China, the prevalence of chronic obstructive pulmonary disease (COPD) is high both in urban and rural area $(1,2)$. The morbidity and mortality of COPD have a trend of increase in recent years. The previous COPD researches demonstrated that frequent exacerbations and accelerated decline of pulmonary function could lead to disease progression (3). Current evidence showed some drugs and interventions could partially delay COPD progression. So it is essential to find indicators to predict the prognosis and outcome of COPD.

As we all know, obesity played a detrimental role in asthma and obstructive sleep apnea hypopnea syndrome (4-6). However, conclusions on the roles of body mass index (BMI) in COPD were discrepant. It has been demonstrated that higher mortality in underweight COPD patients was partially due to the accelerated decline of forced expiratory volume in 1 second $\left(\mathrm{FEV}_{1}\right)(3,7)$. Unfortunately, most clinical studies concentrated on the effect of low weight and severe obesity on the mortality of patients with COPD, but few studies focused on the relationship of BMI and other factors during the progression of COPD (8-12). Moreover, most of the previous studies were only small sample randomized controlled trials, which limited to generalize the conclusions. Therefore, it would be meaningful to add data from real world and study other factors. The aim of our retrospective research was to study the effects of BMI on COPD progression.

\section{Methods}

\section{Study design and patients}

With a retrospective real world research design, all cases with COPD as one of discharge diagnosis in Shandong Provincial Hospital or Shanghai Zhongshan Hospital from January $1^{\text {st }}, 2014$ to December $31^{\text {st }}, 2016$ were gathered from hospital records databases. Patients must be over 40 years old, had records of pulmonary function tests, and be alive when discharged from hospital.

\section{Data collection}

All data during the above mentioned period were sequentially collected by manual extraction from electronic medical records through hospital records databases in two centers, including basic information (gender, age, height and weight), history of smoking, co-morbidities, laboratory blood tests-white blood cell (WBC), neutrophils, eosinophils, C-reactive protein (CRP), pulmonary function tests-forced expiratory volume in 1 second (post bronchodilator $\mathrm{FEV}_{1}$ ), forced expiratory vital capacity (FVC), peak expiratory flow (PEF), forced expiratory flow $\left(\mathrm{FEF}_{25-75}\right)$ and diffusing capacity of carbon monoxide (DLCO), pulmonary arterial pressure (PAP) measured by Doppler cardiac ultrasound, the dose of systemic corticosteroid and length of stay. From March to May of 2017, all recruited patients were followed up by phone calls and hospital record systems to record their moderate and severe acute exacerbation events from January $1^{\text {st }}, 2014$ to December $31^{\text {st }}, 2016$.

\section{Study variables}

BMI was used as the independent variable. According to the standard of the World Health Organization (WHO), all participants were classified into four subgroups, underweight $(\mathrm{BMI}<18.5)$, normal weight $(18.5 \leq \mathrm{BMI}<25)$, overweight $(25 \leq \mathrm{BMI}<30)$ and obesity $(\mathrm{BMI} \geq 30)$.

Parameters in pulmonary function tests and frequency of exacerbation were used as observable variables. (I) post bronchodilator $\mathrm{FEV}_{1}$ \% pred (here after termed $\mathrm{FEV}_{1}$ )was divided into four degrees according to Global Initiative for Chronic Obstructive Lung Disease (GOLD) 2014: GOLD1 (FEV ${ }_{1} \geq 80 \%$ pred), GOLD2 (50\% pred $\leq \mathrm{FEV}_{1}<80 \%$ pred), GOLD3 (30\% pred $\leq \mathrm{FEV}_{1}<50 \%$ pred), GOLD 4 ( $\mathrm{FEV}_{1}<30 \%$ pred). It is widely used to predict the severity of COPD (3). (II) PEF is defined as the maximal flow (or speed). To some degree, it could reflect the condition of airway obstruction, especially when combined with $\mathrm{FEF}_{25}$ to indicate the status of large airways and respiratory muscles strength. (III) FEF is usually presented as intervals of $\mathrm{FEF}_{25}, \mathrm{FEF}_{50}$ and $\mathrm{FEF}_{75}$, which represent $\mathrm{FEF}$ after $25 \% / 50 \% / 75 \%$ of $\mathrm{FVC}$ has been exhaled respectively. $\mathrm{FEF}_{25}$ is an indicator to reflect the flow of the early stage of expiration and will decline if large airway is obstructive. $\mathrm{FEF}_{50}$ and $\mathrm{FFE}_{75}$ reflect the flow of the middle stage and the later stage of expiration. $\mathrm{FEF}_{25-75}$ or $\mathrm{FEF}_{50-75}$ may be more sensitive parameters than $\mathrm{FEV}_{1}$ in the assessment of small airway function. (IV) DLCO is used to reflect pulmonary diffusion function. (V) total times of exacerbations is the sum of moderate and severe exacerbations in three years. The definitions of acute exacerbation and its severities are according to GOLD 2014. 


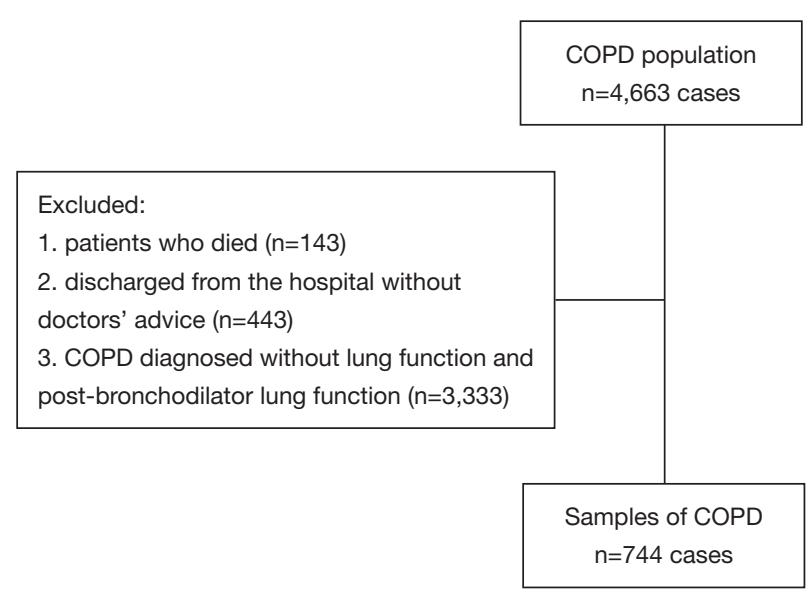

Figure 1 Certainly 744 patients with COPD were recruited. COPD diagnosis was confirmed by pulmonary function test. COPD, chronic obstructive pulmonary disease.

\section{Statistical analysis}

Data collection and record used EpiData (Version 3.1). Statistical analysis was performed using SPSS Version 23.0 (SPSS Inc.; Chicago, Illinois) and GraphPad Prism 7 (GraphPad, San Diego, CA). Parametric data were presented as mean \pm standard error of the mean (SEM) or range. Non-parametric data were presented as median (interquartile range, IQR). We used Spearman bivariate correlations to investigate the correlation of BMI to each indicator. In the primary analysis, Kruskal-Wallis test was used to compare difference among multi-groups and then Mann-Whitney $U$ test was used to compare in pairs. In Kruskal-Wallis test, variation tendency was analyzed by Mean Rank. The chi-squared test $\left(\chi^{2}\right)$ was used to contrast proportions among groups. In the secondary analysis, the ordinal multinomial logistic regression was used to analyze multivariable parameters. $\mathrm{P}<0.05$ was considered as the threshold of significance for all statistical analysis.

\section{Results}

Finally, 744 COPD patients were retained (Figure 1). BMI had mild or moderate positively correlation with $\mathrm{FEV}_{1}$, PEF, $\mathrm{FEF}_{25-75}$ and DLCO (Table 1).

In 744 cases, $77 \%$ were male with a median age (IQR) of 67 years. Among them, $57.53 \%$ were smokers and $32.93 \%$ were non-smokers. The smoking-history of other $9.54 \%$ patients was unclear. According to BMI grades, all cases were classified into four groups as follows: underweight
(58 cases, BMI 17.54), normal weight (342 cases, BMI 22.12), overweight (208 cases, BMI 27.00) and obesity (136 cases, BMI 31.25) (Table 2).

There was no significant difference of WBC count among groups. The percentage of neutrophils presented significant declining trend with the increasing of BMI. As compared to obesity group, the value in each other three groups was significantly higher. But there was no marked difference among underweight, normal weight and overweight groups (Figure $2 A$ ). The percentage of eosinophils in obesity groups was higher than that of underweight, normal weight and overweight groups. The difference was only significant as compared to that of overweight group (Figure 2B). The value of CRP presented declining trend with the increasing of BMI. It was highest in underweight group, which was significantly higher than those of overweight and obesity groups but not that of normal weight group (Figure 2C).

$\mathrm{FEV}_{1}, \mathrm{PEF}$ and DLCO were all significantly increased with the increase of BMI, except for the not significant differences between underweight and normal weight groups in $\mathrm{FEV}_{1}$ and PEF (Figure $3 A, B, C$ ). The overall trend of $\mathrm{FEF}_{25}, \mathrm{FEF}_{50}$ and $\mathrm{FEF}_{75}$ presented increasing with the increase of $\mathrm{BMI}$ (Figure 4). The values of $\mathrm{FEF}_{25}, \mathrm{FEF}_{50}$ and $\mathrm{FEF}_{75}$ in underweight and normal weight groups were similar, which were significantly lower than those of overweight and obesity groups except for $\mathrm{FEF}_{75}$. All $\mathrm{FEF}_{25}$, $\mathrm{FEF}_{50}$ and $\mathrm{FEF}_{75}$ in obesity group were significantly higher than those of overweight group.

All together 271 patients had the Doppler cardiac ultrasound examination. Only the PAP in underweight group was higher than $40 \mathrm{mmHg}$. The PAP value was conversely correlated to BMI. It was markedly lower in obesity population than that of underweight or normal weight groups but not significantly among other groups comparison (Figure 5).

The length of stay and total dosage of systemic corticosteroid were not notably different among four BMI groups (Table 2).

The frequency of total exacerbations and severe exacerbations per year were significantly higher in underweight group than those in other three groups (Figure 6).

\section{Subgroups analysis}

Due to the baseline, such as gender and smoking, was not matched. We analyzed those indicators in each subgroupmale, female, smokers, non-smokers in order to keep the comparability among each BMI grades. 
Table 1 All relative factors and BMI were performed by Spearman bivariate correlations

\begin{tabular}{|c|c|c|c|c|c|c|}
\hline Spearman bivariate correlations & \multicolumn{3}{|c|}{ BMI } & \multicolumn{3}{|c|}{ BMI grades } \\
\hline CRP & -0.164 & $<0.001$ & 475 & -0.125 & 0.007 & 475 \\
\hline WBC & 0.01 & 0.79 & 744 & 0.000 & 0.993 & 744 \\
\hline Neutrophils percent & -0.096 & 0.009 & 744 & -0.088 & 0.017 & 744 \\
\hline $\mathrm{FEV}_{1}$ & 0.29 & $<0.001$ & 744 & 0.275 & $<0.001$ & 744 \\
\hline FVC & 0.127 & 0.001 & 744 & 0.132 & $<0.001$ & 744 \\
\hline PEF & 0.349 & $<0.001$ & 744 & 0.341 & $<0.001$ & 744 \\
\hline $\mathrm{FEF}_{25}$ & 0.282 & $<0.001$ & 740 & 0.254 & $<0.001$ & 740 \\
\hline TLC & 0.038 & 0.323 & 679 & 0.047 & 0.219 & 679 \\
\hline $\mathrm{RV}$ & -0.012 & 0.75 & 679 & 0.000 & 0.993 & 679 \\
\hline DLCO & 0.415 & $<0.001$ & 673 & 0.39 & $<0.001$ & 673 \\
\hline DLCO/VA & 0.464 & $<0.001$ & 677 & 0.43 & $<0.001$ & 677 \\
\hline PAP & -0.128 & 0.035 & 271 & -0.141 & 0.02 & 271 \\
\hline Exacerbations in 3 years & -0.002 & 0.98 & 234 & -0.019 & 0.774 & 234 \\
\hline Moderate exacerbations in 3 years & 0.016 & 0.809 & 234 & 0.014 & 0.837 & 234 \\
\hline Severe exacerbations in 3 years & -0.115 & 0.08 & 234 & -0.129 & 0.049 & 234 \\
\hline
\end{tabular}

$\mathrm{P}<0.05$ means the two indicators were significantly correlated. BMI, body mass index; CRP, $\mathrm{C}$ reactive protein; WBC, white blood cell; FEV1, forced expiratory volume in 1 second; FVC, forced vital capacity; PEF, peak expiratory flow; FEF, forced expiratory flow; TLC, total lung capacity; RV, residual volume; DLCO, diffusing capacity of carbon monoxide; DLCO/VA, ratio of carbon monoxide diffusion capacity to alveolar ventilation; PAP, pulmonary arterial pressure.

In each subgroup, the baseline is equally comparable. The results showed $\mathrm{FEV}_{1}$, PEF, DLCO, $\mathrm{FEF}_{25}, \mathrm{FEF}_{50}$ were all presented significant difference according to BMI deviation in male subgroup and in female subgroup (Table 3). The tendency of $\mathrm{FEF}_{75}$ in male patients was similar to that of whole samples (Table 4). Interestingly, the total lung capacity (TLC) and residual volume (RV) in female patients presented significant increasing trend with the increase of BMI but not in male patients. Like the whole sample, the frequency of severe exacerbation per year in underweight group was much higher than those of other three groups in male patients but not in female patients. $\mathrm{FEV}_{1}, \mathrm{PEF}, \mathrm{FEF}_{25-75}$ and DLCO were significantly lower in underweight group compared to obesity group both in smokers' subgroup (Table 5) and non-smokers subgroup (Table 6). Compared with other three groups, the frequency of exacerbation and severe exacerbation per year of underweight patients was significantly higher in smoking patients. Those results manifested the conclusion of BMI and lung function and exacerbation is available.

\section{Secondary analysis}

$\mathrm{FEV}_{1}$ is the most important indicator for COPD patients in lung function; GOLD grade is an indicator which could be standing for $\mathrm{FEV}_{1}$ level in COPD. We performed ordinal multinomial logistic regression and choose GOLD grades as the dependent variable; age, gender, BMI, smoking status, WBC, neutrophils and eosinophils \%, CRP and $\mathrm{PAP}$ as independent variables. Age, gender, BMI, PAP 
Table 2 Clinical characteristics of total patients with COPD (n=744)

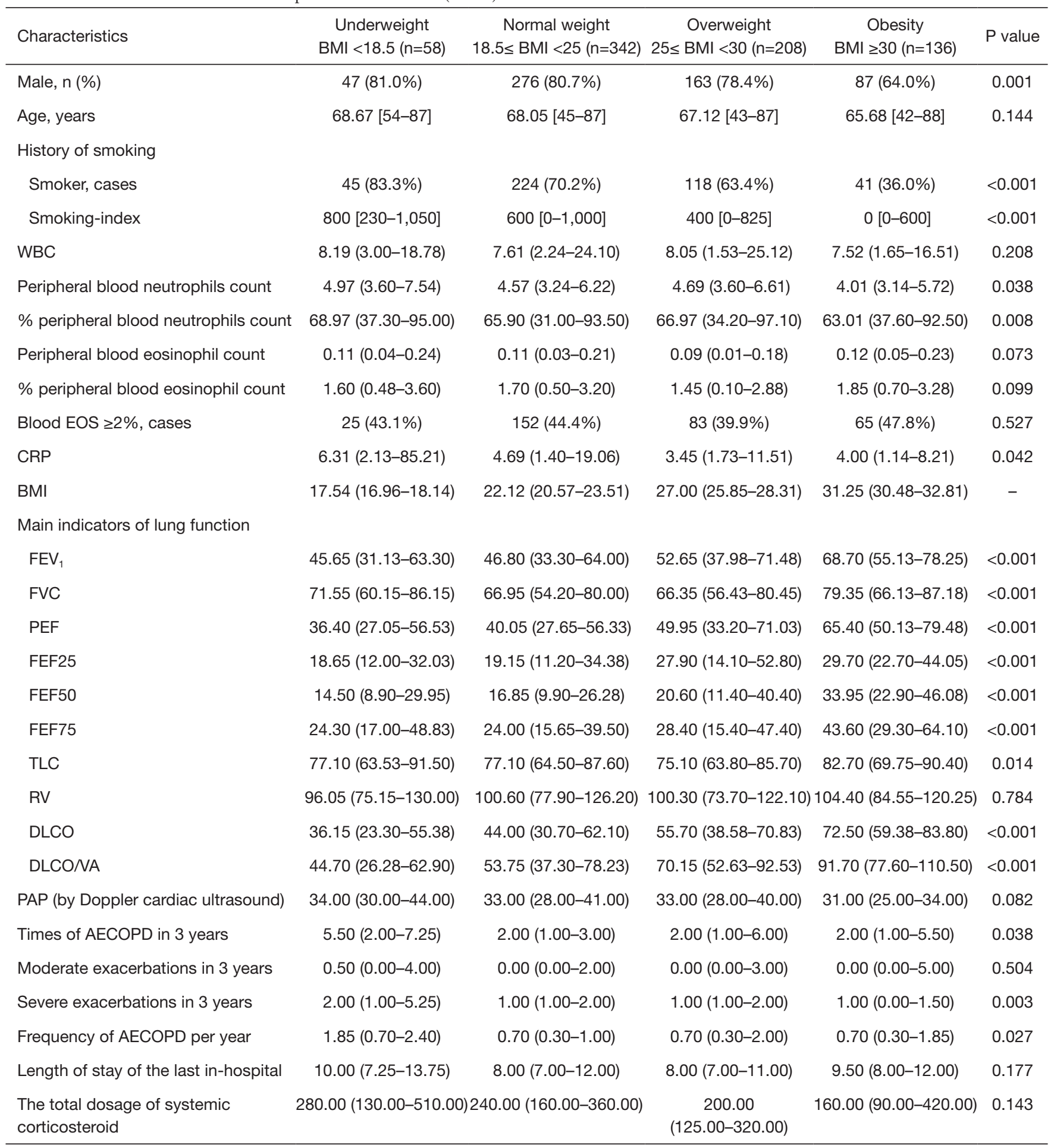

Data presented as median (IQR) unless specified. COPD, chronic obstructive pulmonary disease; BMI, body mass index; WBC, white blood cell; EOS, eosinophil; CRP, C reactive protein; FEV1, forced expiratory volume in 1 second; FVC, forced vital capacity; PEF, peak expiratory flow; FEF, forced expiratory flow; TLC, total lung capacity; RV, residual volume; DLCO, diffusing capacity of carbon monoxide; DLCO/VA, ratio of carbon monoxide diffusion capacity to alveolar ventilation; PAP, pulmonary arterial pressure; AECOPD, acute exacerbation of chronic obstructive pulmonary disease. 
A
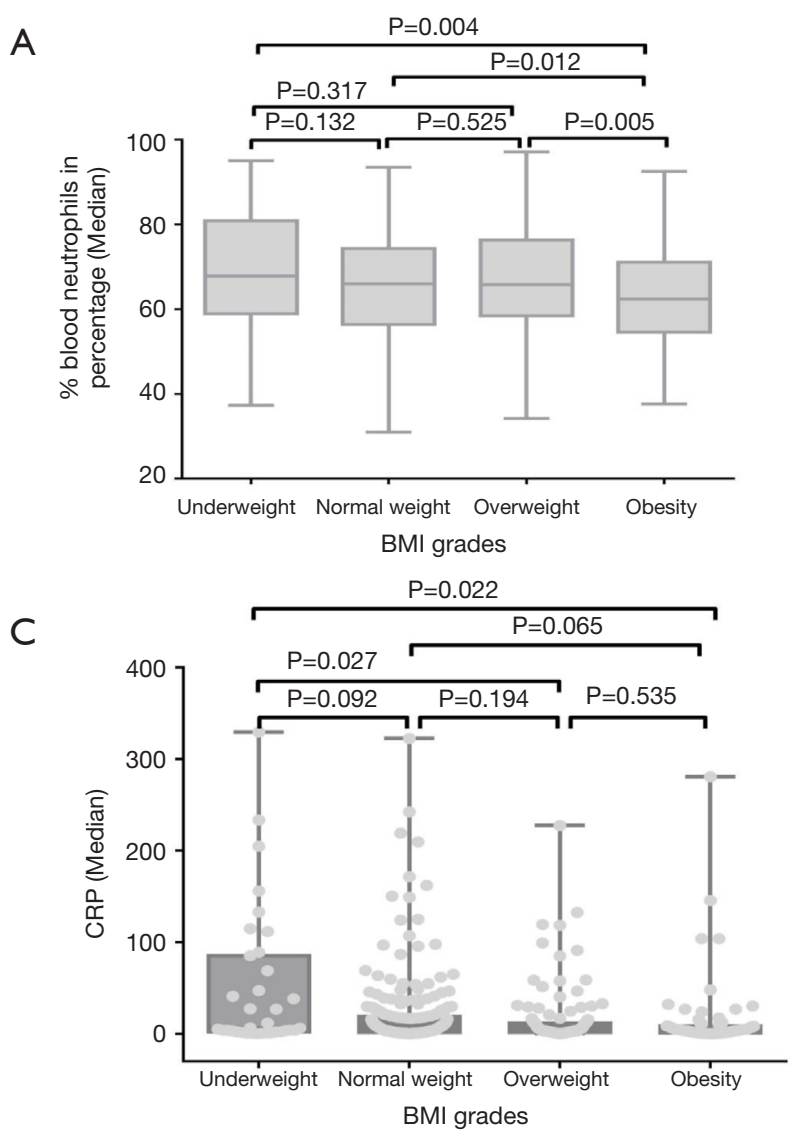

B

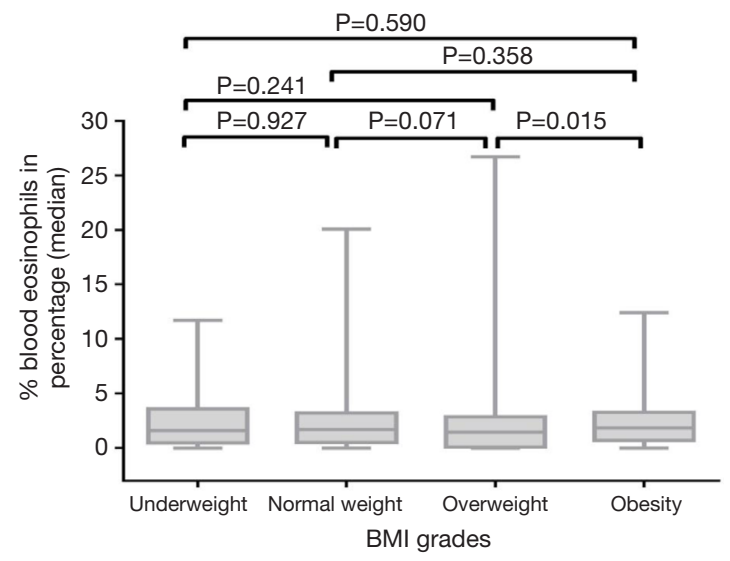

Figure 2 The association between BMI grades and inflammation level in COPD. (A) Median \%neutrophils percent compared in four body mass index (BMI) grades. Box plots represent distributions of majority cases. (B) Median \% eosinophils percent compared in four BMI grades. Box plots represent distributions of majority cases. (C) Median CRP compared in four BMI grades. Box plots and circles represent distributions of majority cases. BMI, body mass index; CRP, C reactive protein.

presented statistical significance. According to the results of optimization model, the Exp value was calculated. Compared with elder COPD patients, the youngers were possibly in better GOLD stages $(\operatorname{Exp}=1.052)$. Compared with female COPD patients, the males were possibly in worse GOLD stages $(\mathrm{Exp}=2.149)$. Compared with obesity class respectively, the underweight and normal weight patients were possibly in worse GOLD stages $(\mathrm{Exp}=3.297$ and $\mathrm{Exp}=2.821)$. Compared with patients with $\mathrm{PAP}>30 \mathrm{mmHg}$ (13), the patients with $\mathrm{PAP} \leq 30 \mathrm{mmHg}$ were possibly in better GOLD stages $(\mathrm{Exp}=0.571)$ (Table 7).

\section{Discussion}

The effect of BMI in the progression of COPD drew lots of attention (14). Our retrospectively real world research demonstrated that in patients with COPD, BMI was positively correlated with pulmonary function and negatively correlated with inflammation levels and acute exacerbations markedly.

It is generally accepted that improving nutrition status, enhancing respiratory muscles strength and reducing inflammation level are effective on long-term management of COPD (15). BMI was considered as an accurate indicator of nutrition in some degree. The prevalence of sarcopenia was common in COPD patients, especially in severe, elder or underweight patients (16). As shown in our results, compared to patients with COPD in lower BMI, those in higher BMI (overweight and obesity) had better pulmonary function, lower inflammation level (lower CRP and neutrophils) and less exacerbation. Better pulmonary function in our study were higher $\mathrm{FEV}_{1} \%$ pred to show 
A

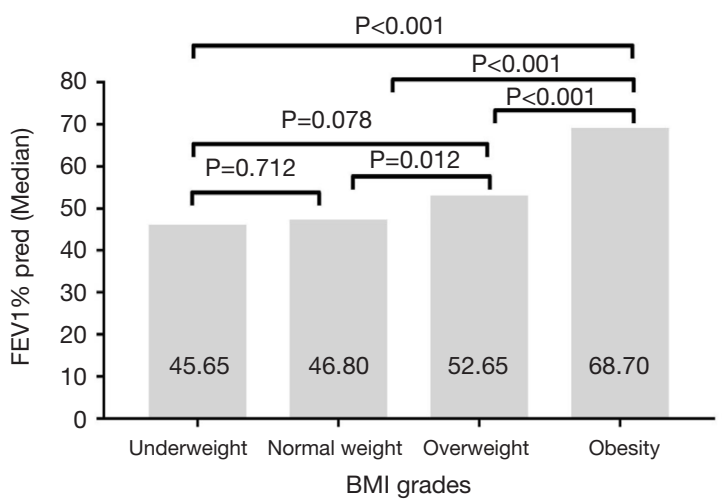

C

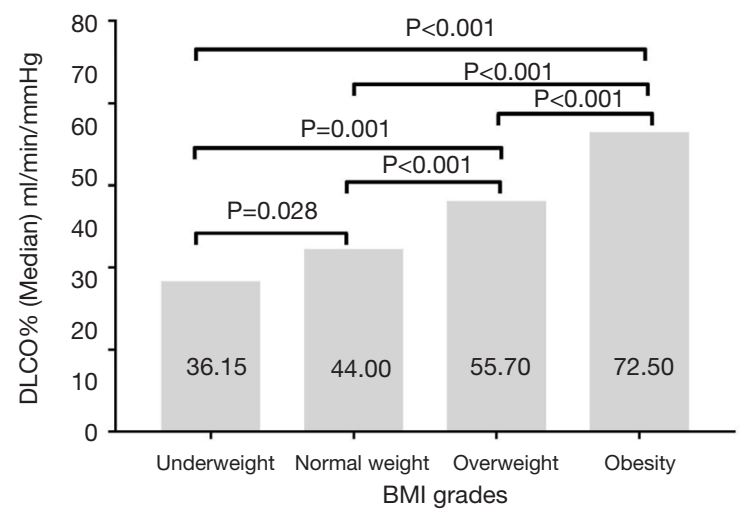

B

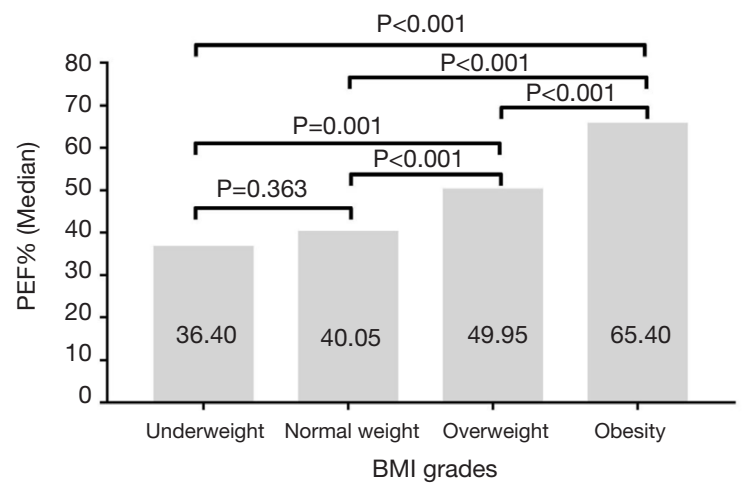

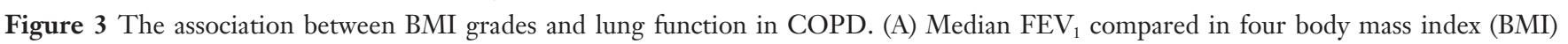
grades. Values show the medians. Bars represent medians. (B) Median PEF compared in four BMI grades. Values show the medians. Bars represent medians. (C) Median DLCO compared in four BMI grades. Values show the medians. Bars represent medians. BMI, body mass index. $\mathrm{FEV}_{1}$, forced expiratory volume in 1 second; PEF, peak expiratory flow; DLCO, diffusing capacity of carbon monoxide.

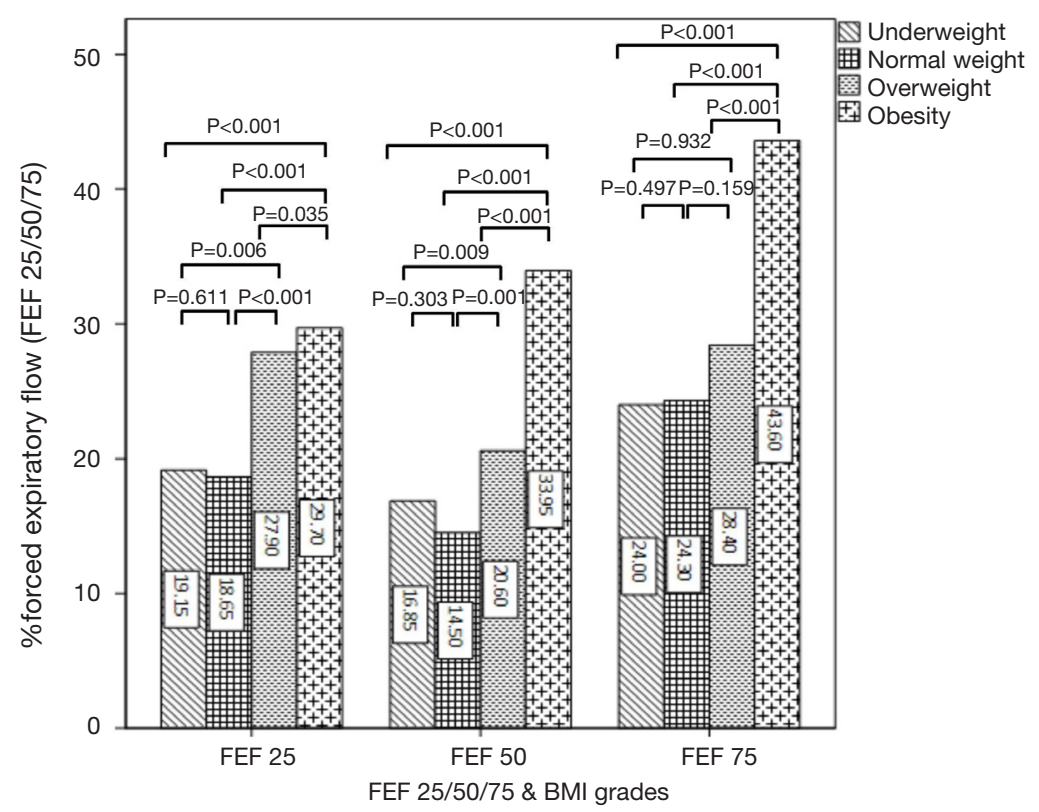

Figure 4 Median FEF25\%/50\%/75\% compared in four body mass index (BMI) grades. Different lines style means different BMI grades. Bars represent medians. FEF25\%/50\%/75\%, forced expiratory flow after 25\%, 50\%, $75 \%$. 
slighter airway obstruction, higher PEF and $\mathrm{FEF}_{25}$ or $\mathrm{FEF}_{50}$ and $\mathrm{FEF}_{75}$ to indicate better major or small airways function, and higher DLCO to present better lung diffusion function. In our study, no matter in total samples or subgroups divided by gender, smoking status, acute or stable COPD, the results were all consistent. All above results indicated that the overall prognosis might be better with higher BMI. We hypothesized the reasons might be: firstly, even though we did not analyze COPD patients in "blue

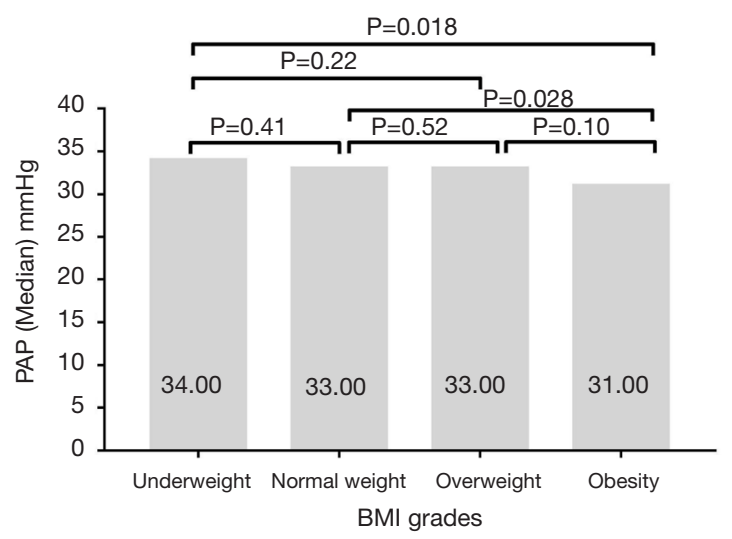

Figure 5 Median PAP compared in four body mass index (BMI) grades. Values show the medians. Bars represent medians. PAP, pulmonary arterial pressure. bloater" or "pink puffer" clinical phenotypes, generally speaking, overweight and obesity COPD patients might have more nutrition intake and be in better nutrition status than underweight patients; secondly, bigger in size might let the patients have more and stronger muscles to facilitate breathing. Then, they could do more exercise and had more and stronger muscles in turn; thirdly, lower inflammation level could reduce the possibility of acute exacerbations (15,17-22). Therefore, BMI might be an important indicator to evaluate COPD patients' condition and longterm chronic diseases management.

Due to innate idea, some doctors think that obesity people may have glucocorticoid resistance (23), which seems that patients with COPD in obesity might need higher systemic corticosteroid doses and longer treatment for acute exacerbations. On the contrary, our research showed decreasing tendency in dose of systemic corticosteroid and length of stay with increasing of BMI grades, which also demonstrated that higher BMI might be a protective factor.

We further analyzed the effect of smoking. Different from non-smoking patients, acute moderate-severe exacerbations happened significantly less with the increase of $\mathrm{BMI}$ grades in smoking subgroups. In male COPD patients, the smokers were the majority and the exacerbations was significantly less with the increase of BMI. So, it would be important for male, smoking, underweight COPD patients

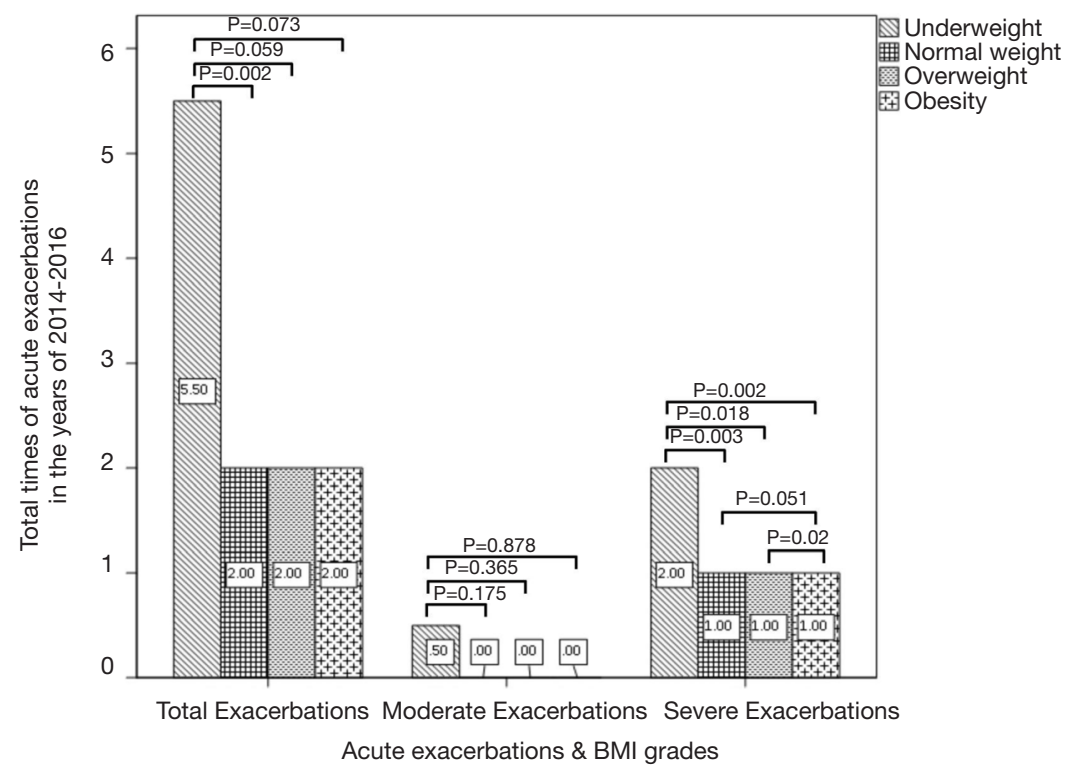

Figure 6 Different BMI grades, different lines style represents the frequency of different severity of COPD exacerbation. Values show the medians. COPD, chronic obstructive pulmonary disease; BMI, body mass index. 
Table 3 Compared main indicators in male subgroup

\begin{tabular}{|c|c|c|c|c|c|}
\hline Research indicators & \multicolumn{5}{|c|}{ Male subgroup } \\
\hline \multicolumn{6}{|c|}{ Main indicators of lung function } \\
\hline $\mathrm{FEV}_{1}$ & $46.10(29.80-63.90)$ & $44.30(32.43-62.98)$ & $50.30(34.50-69.80)$ & $68.60(52.80-78.30)$ & $<0.001$ \\
\hline $\mathrm{FEF}_{25}$ & $18.60(8.70-33.30)$ & $18.15(10.90-34.25)$ & $26.80(13.10-47.40)$ & $29.70(23.15-43.35)$ & $<0.001$ \\
\hline $\mathrm{FEF}_{50}$ & $14.45(8.73-32.58)$ & $15.30(9.60-26.58)$ & $20.30(11.00-38.70)$ & $33.70(22.80-51.20)$ & $<0.001$ \\
\hline $\mathrm{FEF}_{75}$ & 24.30 (16.43-49.08) & $22.85(14.90-38.20)$ & $25.10(14.90-44.20)$ & $44.45(28.75-65.30)$ & $<0.001$ \\
\hline DLCO/NA* & $47.52(5.70-116.70)$ & $56.32(1.29-185.50)$ & $71.61(1.69-186.30)$ & $97.03(43.90-171.80)$ & $<0.001$ \\
\hline $\begin{array}{l}\text { PAP (by Doppler cardiac } \\
\text { ultrasound) }\end{array}$ & $34.00(31.00-44.00)$ & $34.00(28.00-41.75)$ & $34.50(28.00-41.25)$ & $32.00(28.50-34.00)$ & 0.252 \\
\hline $\begin{array}{l}\text { Times of AECOPD in } \\
\text { years }\end{array}$ & $6.00(2.50-8.75)$ & $2.00(1.00-4.00)$ & $2.00(1.00-5.75)$ & $2.00(1.00-5.75)$ & 0.110 \\
\hline $\begin{array}{l}\text { Moderate exacerbations in } \\
3 \text { years }\end{array}$ & $1.00(0.00-4.25)$ & $0.00(0.00-2.00)$ & $0.00(0.00-2.75)$ & $1.00(0.00-5.50)$ & 0.257 \\
\hline $\begin{array}{l}\text { Severe exacerbations in } \\
3 \text { years }\end{array}$ & $2.50(1.00-5.25)$ & $1.00(1.00-2.00)$ & $1.00(1.00-1.75)$ & $0.50(0.00-1.00)$ & 0.003 \\
\hline
\end{tabular}

Data presented as median (IQR) unless specified. *, data presented as mean (range). BMI, body mass index; FEV ${ }_{1}$, forced expiratory volume in 1 second; FVC, forced vital capacity; PEF, peak expiratory flow; FEF, forced expiratory flow; TLC, total lung capacity; RV, residual volume; DLCO, diffusing capacity of carbon monoxide; DLCO/NA, ratio of carbon monoxide diffusion capacity to alveolar ventilation; PAP, pulmonary arterial pressure; AECOPD, acute exacerbation of chronic obstructive pulmonary disease.

to gain higher $\mathrm{BMI}$ in order to improve their prognosis. Interestingly, Schermer et al. also recently supported our results and indicated that higher BMI might be beneficial to ameliorate airway obstruction (24).

In our study, most of patients with COPD in obesity were in obesity class I (BMI 30-34.9 kg/m²) (25), which were similar to the BMI distribution in total Chinese population (26). We found patients with COPD in $\mathrm{BMI} \geq 25$ (overweight and obesity class I) had better pulmonary function, less exacerbations, lower PAP and lower inflammation level, compared with patients with COPD in underweight. Our results are partially opposite to some previous studies. Lambert's research showed patients with COPD in obesity were prevalent, and the increase of BMI was related to co-morbidities increasing, life quality declining, pulmonary function damaging, severe exacerbation risk rising and worse prognosis (10). Chilean researchers held the idea that CRP was weakly associated with fat mass/BMI and frequency of exacerbations (27). Weinreich et al. and Pekkarinen et al. considered lean body mass positively correlated with DLCO $(28,29)$. The reason for this phenomenon is possibly that COPD patients in obesity in our study were all in lower obesity grade (BMI $30-34.9 \mathrm{~kg} / \mathrm{m}^{2}$ ), compared with COPD patients from western countries (nearly half of obesity patients were in $\mathrm{BMI} \geq 35 \mathrm{~kg} / \mathrm{m}^{2}$ ), this phenomenon is more consistent with 


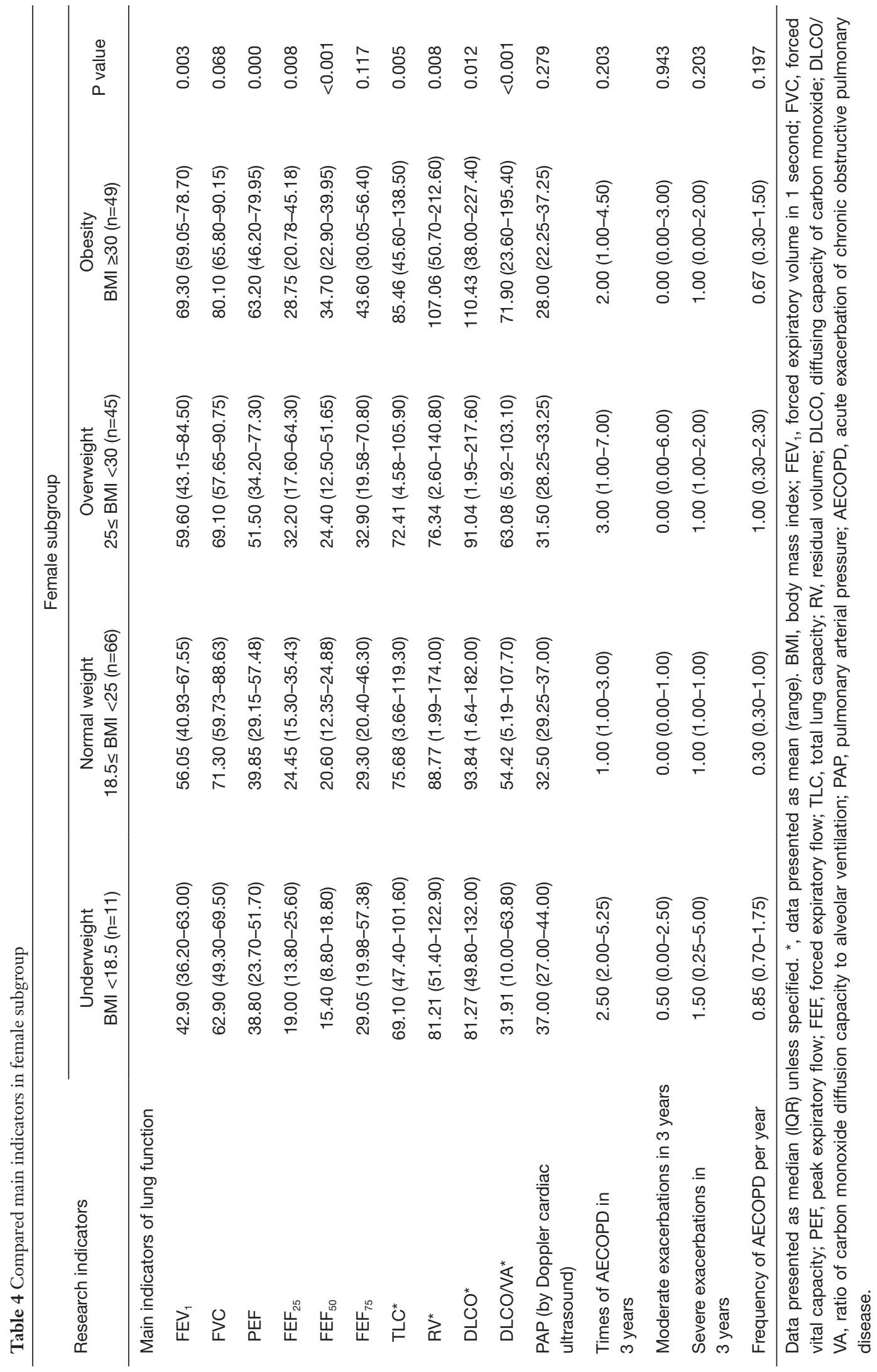


Table 5 Compared main indicators in smokers subgroup

\begin{tabular}{|c|c|c|c|c|c|}
\hline Research indicators & \multicolumn{5}{|c|}{ Smoker subgroup } \\
\hline \multicolumn{6}{|c|}{ Main indicators of lung function } \\
\hline $\mathrm{FEV}_{1}$ & $46.20(30.35-68.40)$ & $44.25(32.43-60.18)$ & $55.15(37.95-75.00)$ & $68.60(52.15-76.85)$ & $<0.001$ \\
\hline $\mathrm{FEF}_{25}$ & $20.00(11.90-41.80)$ & $18.00(10.80-32.45)$ & $30.00(14.20-53.05)$ & $30.00(24.00-47.90)$ & $<0.001$ \\
\hline $\mathrm{FEF}_{50}$ & $14.80(9.70-35.20)$ & $15.30(9.60-24.88)$ & $23.85(11.88-41.55)$ & $34.00(19.80-48.70)$ & $<0.001$ \\
\hline $\mathrm{FEF}_{75}$ & 28.90 (16.70-49.35) & $23.40(15.48-37.13)$ & $30.95(15.35-45.43)$ & $41.50(27.25-65.60)$ & $<0.001$ \\
\hline DLCO/NA* & $45.80(27.25-63.30)$ & $49.25(35.43-72.33)$ & $71.30(51.40-89.75)$ & $97.70(79.23-118.30)$ & $<0.001$ \\
\hline $\begin{array}{l}\text { PAP (by Doppler cardiac } \\
\text { ultrasound) }\end{array}$ & $33.00(30.00-43.50)$ & $33.00(28.00-42.00)$ & $31.00(28.00-38.50)$ & $31.00(28.00-35.00)$ & 0.434 \\
\hline $\begin{array}{l}\text { Times of AECOPD in } \\
3 \text { years }\end{array}$ & $6.00(3.00-8.75)$ & $2.00(1.00-3.00)$ & $2.00(1.00-6.00)$ & $2.00(1.00-5.50)$ & 0.045 \\
\hline $\begin{array}{l}\text { Moderate exacerbations } \\
\text { in } 3 \text { years }\end{array}$ & $2.50(0.00-4.25)$ & $0.00(0.00-2.00)$ & $0.00(0.00-3.00)$ & $1.00(0.00-5.00)$ & 0.221 \\
\hline $\begin{array}{l}\text { Severe exacerbations in } \\
3 \text { years }\end{array}$ & $2.50(1.00-5.25)$ & $1.00(1.00-2.00)$ & $1.00(1.00-2.00)$ & $1.00(0.00-1.00)$ & 0.015 \\
\hline
\end{tabular}

Data presented as median (IQR) unless specified. *, data presented as mean (range). BMI, body mass index; FEV ${ }_{1}$, forced expiratory volume in 1 second; FVC, forced vital capacity; PEF, peak expiratory flow; FEF, forced expiratory flow; TLC, total lung capacity; RV, residual volume; DLCO, diffusing capacity of carbon monoxide; DLCO/NA, ratio of carbon monoxide diffusion capacity to alveolar ventilation; PAP, pulmonary arterial pressure; AECOPD, acute exacerbation of chronic obstructive pulmonary disease.

the characteristics of Asians (10,25,26,30,31). Notably, in recent years, occidental researchers got the "Obesity paradox" conclusion in COPD domain. A research by Paul Stoll with 75 COPD patients showed that overweight and obesity were positive predictors of long-term survival in COPD patients $(2,11)$.

For COPD patients in China, treatment is not standard; medication adherence is poor; and morbidity of COPD is still high $(1,2)$. From our results, the healthy and properly body weight is good for long term management of COPD patients. This will be suitable for current Chinese condition, even Asian. The patients of this study were from Shandong Province Hospital and Shanghai Zhongshan Hospital.
Their economic status, education levels and healthcare situation were similar to others from eastern China. So the conclusions of this study are representative. As we all know, obesity is a double-edged sword. In future studies, we will try to provide an optimal BMI cutoff point for patients with COPD to obtain benefits of better pulmonary function, lower level of inflammation and fewer exacerbations. There is a limitation that patients were followed-up three years frequency of AECOPD may have recall-bias in this retrospective research. Another, BMI may be not a good indicator to reflex the status of nutrition and muscles. So in next perspective study, we will pay attention to the role of body composition and fat free mass index in COPD patients. 


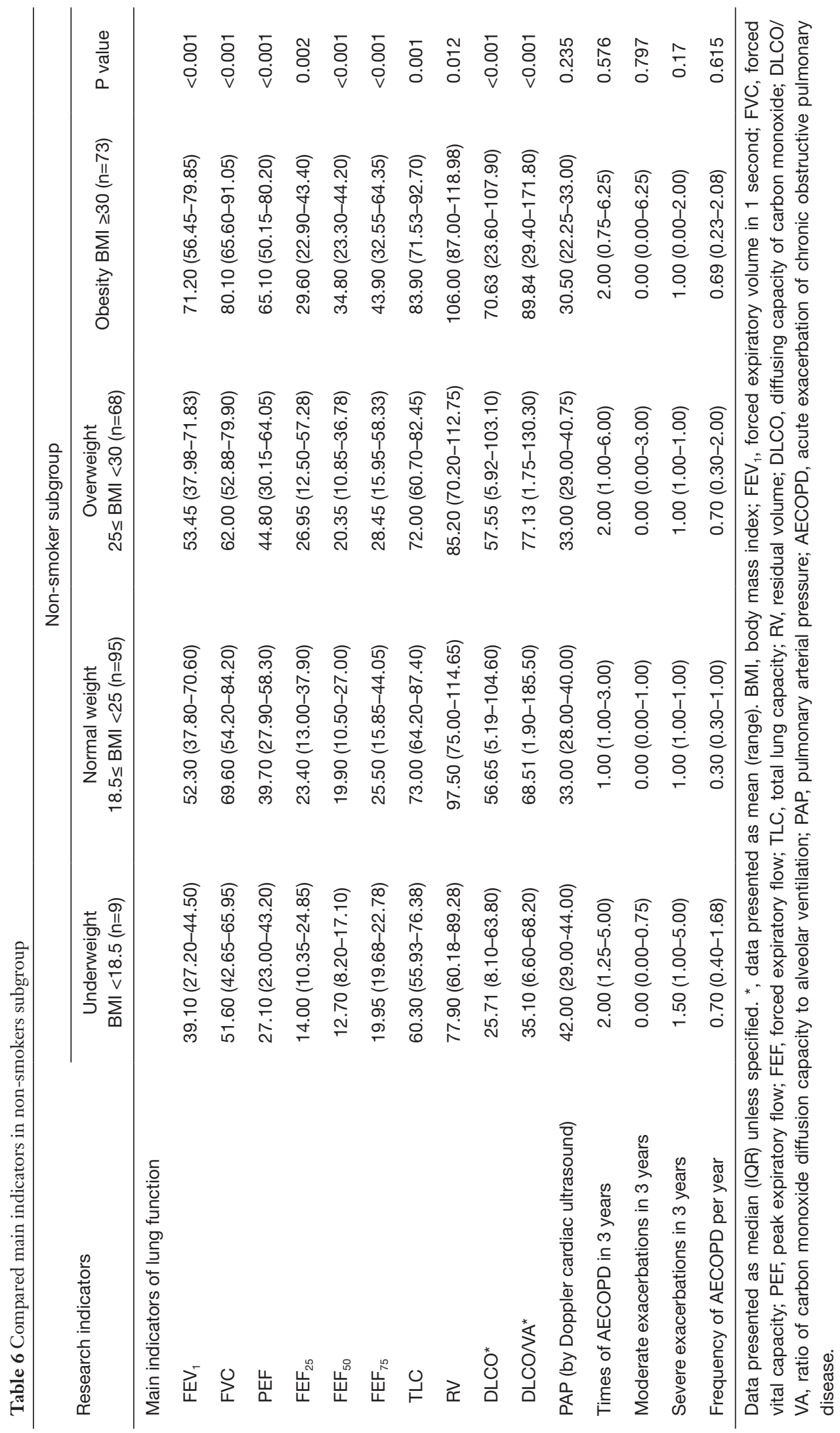


Table 7 The optimization model of ordinal multinational logistic regression

\begin{tabular}{|c|c|c|c|c|c|c|c|}
\hline Factors in model & Estimate & Std. Error & Wald & $d f$ & $P$ value & \multicolumn{2}{|c|}{$95 \% \mathrm{Cl}$} \\
\hline \multicolumn{8}{|l|}{ Threshold } \\
\hline GOLD 2 & -2.473 & 0.969 & 6.509 & 1 & 0.011 & -4.374 & -0.573 \\
\hline GOLD 3 & -0.566 & 0.956 & 0.351 & 1 & 0.554 & -2.441 & 1.308 \\
\hline Age & -0.051 & 0.013 & 15.198 & 1 & 0 & -0.077 & -0.025 \\
\hline Male & 0.765 & 0.271 & 7.983 & 1 & 0.005 & 0.234 & 1.296 \\
\hline Female $^{a}$ & 0 & 0 & 0 & 0 & 0 & 0 & 0 \\
\hline Underweight & 1.193 & 0.458 & 6.799 & 1 & 0.009 & 0.296 & 2.09 \\
\hline $\mathrm{PAP} \leq 30 \mathrm{mmHg}$ & -0.560 & 0.241 & 5.371 & 1 & 0.02 & -1.033 & -0.086 \\
\hline $\mathrm{PAP}>30 \mathrm{mmHg}^{\mathrm{a}}$ & 0 & 0 & 0 & 0 & 0 & 0 & 0 \\
\hline
\end{tabular}

${ }^{a}$, this parameter is redundant; therefore it is set to zero. GOLD, global initiative for chronic obstructive lung disease; PAP, pulmonary arterial pressure; Std. Error, standard error; $\mathrm{Cl}$, confidence interval.

\section{Conclusions}

In our study, with the increase of BMI, the pulmonary function improved while the inflammation level and frequencies of exacerbations decreased. So, BMI might be a useful indicator to predict the prognosis of patients with COPD. This study provided a good idea for further related research and COPD long-term management.

\section{Acknowledgements}

We should give our thanks to the medical record department of Shandong Provincial Hospital to offer those COPD patients' hospitalization records.

Funding: This work was partially supported by Natural Science Foundation of China (Project number: 81300030, 81570336).

\section{Footnote}

Conflicts of Interest: The authors report no conflicts of interest in this work.

Ethical Statement: As there was a retrospective study, no randomization, no new treatment being explored and no potential harm to the patients. This study was approved by
Shandong Provincial Hospital Medical Ethics Committee (Ethical Review of Medical Research on Human Being No. 2016-23).

\section{References}

1. Zhong N, Wang C, Yao W, et al. Prevalence of chronic obstructive pulmonary disease in China: a large, populationbased survey. Am J Respir Crit Care Med 2007;176:753-60.

2. Wang $\mathrm{C}, \mathrm{Xu}$ J, Yang L, et al. Prevalence and risk factors of chronic obstructive pulmonary disease in China (the China Pulmonary Health [CPH] study): a national cross-sectional study. Lancet 2018;391:1706-17.

3. From the Global Strategy for the Diagnosis, Management and Prevention of COPD, Global Initiative for Chronic Obstructive Lung Disease (GOLD) 2014. Available online: http://goldcopd.org

4. Peters U, Dixon AE. Obesity and asthma. J Allergy Clin Immunol 2018;141:1169-79.

5. Senaratna CV, Perret JL, Lodge CJ, et al. Prevalence of obstructive sleep apnea in the general population: A systematic review. Sleep Med Rev 2017;34:70-81.

6. Mathew JL, Narang I. Sleeping too close together: obesity and obstructive sleep apnea in childhood and adolescence. Paediatr Respir Rev 2014;15:211-8. 
7. Kivimäki M, Shipley MJ, Bell JA, et al. Underweight as a risk factor for respiratory death in the Whitehall cohort study: exploring reverse causality using a 45 -year followup. Thorax 2016;71:84-5.

8. Guo Y, Zhang T, Wang Z, et al. Body mass index and mortality in chronic obstructive pulmonary disease: A dose-response meta-analysis. Medicine (Baltimore) 2016;95:e4225.

9. Eriksson B, Backman H, Bossios A, et al. Only severe COPD is associated with being underweight: results from a population survey. ERJ Open Res 2016;2:00051-2015.

10. Lambert AA, Putcha N, Drummond MB, et al. Obesity Is Associated With Increased Morbidity in Moderate to Severe COPD. Chest 2017;151:68-77.

11. Stoll P, Foerster S, Virchow JC. Overweight is a predictor of long-term survival in hospitalized patients with exacerbations of COPD. Respir Med 2016;116:59-62.

12. Jordan JG, Mann JR. Obesity and mortality in persons with obstructive lung disease using data from the NHANES III. South Med J 2010;103:323-30.

13. Zhang RF, Zhou L, Ma GF, et al. Diagnostic value of transthoracic Doppler echocardiography in pulmonary hypertension: a meta-analysis. Am J Hypertens 2010;23:1261-4.

14. Prescott E, Almdal T, Mikkelsen KL, et al. Prognostic value of weight change in chronic obstructive pulmonary disease: results from the Copenhagen City Heart Study. Eur Respir J 2002;20:539-44.

15. Vanfleteren LEGW, Spruit MA, Wouters EFM. Management of chronic obstructive pulmonary disease beyond the lungs. Lancet Respir Med 2016;4:911-24.

16. Jones SE, Maddocks M, Kon SS, et al. Sarcopenia in COPD: prevalence, clinical correlates and response to pulmonary rehabilitation. Thorax 2015;70:213-8.

17. Hallin R, Koivisto-Hursti UK, Lindberg E. Nutritional status, dietary energy intake and the risk of exacerbations in patients with chronic obstructive pulmonary disease (COPD). Respir Med 2006;100:561-7.

18. Skyba P, Kluchova Z, Joppa P, et al. Nutritional status in relation to respiratory impairment and systemic inflammation in patients with acute exacerbations of COPD. Med Sci Monit 2009;15:CR528-33.

19. Landbo C, Prescott E, Lange P, et al. Prognostic value of nutritional status in chronic obstructive pulmonary disease. Am J Respir Crit Care Med 1999;160:1856-61.

20. Ora J, Laveneziana P, Wadell K, et al. Effect of obesity on respiratory mechanics during rest and exercise in COPD. J Appl Physiol (1985) 2011;111:10-9.
21. Sexton P, Metcalf P, Kolbe J. Respiratory effects of insulin sensitisation with metformin: a prospective observational study. COPD 2014;11:133-42.

22. Jeon YK, Shin MJ, Kim WJ, et al. The relationship between pulmonary function and bone mineral density in healthy nonsmoking women: the Korean National Health and Nutrition Examination Survey (KNHANES) 2010. Osteoporos Int 2014;25:1571-6.

23. Anderson WJ, Lipworth BJ. Does body mass index influence responsiveness to inhaled corticosteroids in persistent asthma? Ann Allergy Asthma Immunol 2012;108:237-42.

24. Schermer TR, Robberts B, Crockett AJ, et al. Should the diagnosis of COPD be based on a single spirometry test? NPJ Prim Care Respir Med 2016;26:16059.

25. Executive summary of the clinical guidelines on the identification, evaluation, and treatment of overweight and obesity in adults. Arch Intern Med 1998;158:1855-67.

26. Yang L, Zhou M, Smith M, et al. Body mass index and chronic obstructive pulmonary disease-related mortality: a nationally representative prospective study of 220,000 men in China. Int J Epidemiol 2010;39:1027-36.

27. Díaz O, Parada A, Ramos C, et al. C-Reactive protein levels in patients with chronic obstructive pulmonary disease. Revista Médica De Chile 2012;140:569-78.

28. Weinreich UM, Thomsen LP, Brock C, et al. Diffusion capacity of the lung for carbon monoxide - A potential marker of impaired gas exchange or of systemic deconditioning in chronic obstructive lung disease? Chron Respir Dis 2015;12:357-64.

29. Pekkarinen E, Vanninen E, Länsimies E, et al. Relation between body composition, abdominal obesity, and lung function. Clin Physiol Funct Imaging 2012;32:83-8.

30. Lim JU, Lee JH, Kim JS, et al. Comparison of World Health Organization and Asia-Pacific body mass index classifications in COPD patients. Int J Chron Obstruct Pulmon Dis 2017;12:2465-75.

31. Yamauchi Y, Hasegawa W, Yasunaga H, et al. Paradoxical association between body mass index and in-hospital mortality in elderly patients with chronic obstructive pulmonary disease in Japan. Int J Chron Obstruct Pulmon Dis 2014;9:1337-46.

Cite this article as: Wu Z, Yang D, Ge Z, Yan M, Wu N, Liu Y. Body mass index of patients with chronic obstructive pulmonary disease is associated with pulmonary function and exacerbations: a retrospective real world research. J Thorac Dis 2018;10(8):5086-5099. doi: 10.21037/jtd.2018.08.67 